\title{
Assessment of Prevalence of Malnutrition and Its Associated Factors among AIDS Patients from Asella, Oromia, Ethiopia
}

\author{
Teferi Teklu $\mathbb{D}^{1},{ }^{1}$ Nitin Mahendra Chauhan $\mathbb{D}^{2},{ }^{2}$ Firaol Lemessa ${ }^{(D)},{ }^{1}$ and Getu Teshome $\mathbb{D}^{1}$ \\ ${ }^{1}$ Department of Public Health, College of Health Sciences, Arsi University, Arsi, Ethiopia \\ ${ }^{2}$ Department of Biology, College of Natural and Computational Sciences, Dilla University, 419, Dilla, SNNPR, Ethiopia
}

Correspondence should be addressed to Nitin Mahendra Chauhan; nitinchauhan84@hotmail.com

Received 6 August 2020; Revised 20 November 2020; Accepted 30 November 2020; Published 8 December 2020

Academic Editor: Obinna Ikechukwu Ekwunife

Copyright (C) 2020 Teferi Teklu et al. This is an open access article distributed under the Creative Commons Attribution License, which permits unrestricted use, distribution, and reproduction in any medium, provided the original work is properly cited.

\begin{abstract}
Sub-Saharan Africa remains to be the most heavily affected region by malnutrition, accounting for $23.8 \%$ share of the global burden. Undernutrition weakens the immune system, increases the susceptibility to infections, and may worsen the impact on various kinds of diseases. Our aim was to assess undernutrition and its associated factors among AIDS-infected adult patients from Asella, Oromia Region, Ethiopia. An institutional-based cross-sectional study design was employed from June to July 2018. A total number of 519 patients were selected for the proposed work. Data was entered into EpiData, checked, coded, and analyzed using SPSS version 21 software. Descriptive statistics were used to assess the prevalence of undernutrition among patients. Bivariate and multivariate regressions were used to determine the relationship between undernutrition and its associated factors among the study participants. The results of our study showed that the overall prevalence of undernutrition was $18.3 \%$; out of which $12.7 \%$ were mildly and $5.6 \%$ were moderately to severely undernourished, respectively. Monthly income (AOR: 3.589 , 95\% CI (1.469-8.768)), whole grain feeding (AOR: 2.979, 95\% CI (1.252-7.088)), opportunistic infections in the last six months (AOR: 3.683, 95\% CI (3.075-4.411)), clinical stage (AOR: 2.998, 95\% CI (1.269-7.083)), and insufficient quality of food (AOR: 3.149 , 95\% CI (1.339-7.406)) were found to be significantly associated with undernutrition in this study. Therefore, HIV treatment facility should be supported with nutritional assessment, supplementation, counseling, care, and support to patients that may possibly alleviate this predicament.
\end{abstract}

\section{Introduction}

Human immunodeficiency virus (HIV) epidemic remains one of the major public health challenges globally. In 2018, 37.9 million peoples were living with HIV and 1.7 million with new HIV infections have been reported worldwide $[1,2]$. More than 800 million peoples worldwide are chronically undernourished of which 200 million are living in SubSaharan Africa (SSA), and greater than 33 million are living with HIV infection $[3,4]$. An estimated $0.8 \%$ of adolescents aged between 15 and 49 years worldwide are living with HIV currently. The burden of the epidemic continues to differ considerably between countries and regions. Sub-Saharan Africa remains most severely affected, with an early 1 in every 20 adults living with HIV and accounting for $71 \%$ of the people living with HIV globally [5].
The first evidence of HIV epidemic in Ethiopia was detected in 1984. Ethiopia was labeled to have the biggest epidemic with $1.5 \%$ of HIV prevalence adult peoples aged in the range 15 to 49 years, among 5 SSA [6]. Based on the 2014 estimate, 367,000 patients are taking antiretroviral therapy (ART). However, the need for ART is 542,121 for adults and 178,500 for children under 15 years of age for the year 2014 [7].

Food and nutrition are the basic needs for health, growth, and development, but in Africa, it has been a long-standing challenge to provide sufficient food and nutrition, which is also exacerbated by the human immunodeficiency virus/acquired immunodeficiency syndrome (HIV/AIDS) pandemic. Food is one of the most important needs of people with HIV/AIDS [8]. In resource-limited settings, many people living with HIV/AIDS lack access to sufficient quantities of nutritional 
foods, which poses additional challenges to the success of highly active antiretroviral therapy (HAART) $[9,10]$.

Nutrition and HIV are strongly related to each other since any immune impairment as a result of HIV/AIDS leads to malnutrition, and malnutrition leads to immune impairment, worsens the effect of HIV, and contributes to more rapid progression to AIDS. Asymptomatic HIV-positive individuals require $10 \%$ more energy, and symptomatic $\mathrm{HIV}$-positive individuals require $20-30 \%$ more energy than HIV-negative individuals of the same age, sex, and physical activity level. Low food intake combined with increased energy demands are the major factors in HIV-related weight loss and wasting [11].

Studies have shown that sociodemographic factors also have an effect on nutritional status. Meta-analysis of 11 Sub-Saharan countries including Ethiopia identified that the magnitude of malnutrition among HIV patients varies by wealth status, educational attainment, occupation, and type of residence [12]. The Ghanaian study identified that nutritional status was significantly associated with marital status, income per month, educational level, and large family size [13]. Similarly, another study from Gondar identified that marital status, income, duration of treatment, eating problem, and current status of the patient are significantly associated with undernutrition [14].

Though HIV/AIDS is known to aggravate the occurrence of undernutrition, there is no study conducted to evaluate the effect in the study area. Therefore, the aim of our study is to assess the prevalence of malnutrition and factors associated with HIV/AIDS peoples from Asella, Oromia Region, Ethiopia.

\section{Materials and Methods}

2.1. Study Area and Study Design. A facility-based crosssectional study was conducted among HIV adult patients receiving HAART in Assela Town, Oromia, Ethiopia. The town is located in Arsi Zone, Oromia, Ethiopia, and is situated at a distance of 175 kilometers to the southeast of Addis Ababa, the capital city of Ethiopia [15]. According to the Asella Town Administration Office report (2018/2019), the current population of Asella Town is estimated to be 110,433 with proportion of 55,990 males and 54,443 females [16]. The study was conducted from June to July 2018.

2.2. Sampling Procedure. The sample size, i.e., 519, was determined by using the formula for single population proportion by considering the following assumptions: a 95\% confidence level, 5\% margin of error, and $p=31 \%$ from the estimated proportion of malnutrition and associated factors among adult individuals on HAART in Asella [16]. Followed by $10 \%$ nonresponse rate was added. Finally, the correction formula was used as source of population less than 10,000 and was modified to 3984 .

All public health facilities in Asella Town providing ART service were included in the study. From the total of 4324 people living with HIV (PLHIV), 3984 (3356 from Asella Hospital and 628 Asella Health Center) were adults above 15 years of age. Therefore, in order to select 519 participants from 3984 PLHIV proportionately, 437 from Asella Hospital and 82 from Asella Health Center were selected. Based on eligibility criteria people living with HIV on HAART, a systematic random sampling was used to select samples (clinical record of patients on log book). Sampling interval $k^{\text {th }}$ was determined by dividing the total patients actively on ART in each of the health facilities by the required sample size $\left(K^{\text {th }}=N / n=3984 / 519=8\right)$. From the total PLHIV on HAART in sample, the first clinical record was selected by a simple random sampling and every $8^{\text {th }}$ client was selected for gathering information until the required sample was obtained. Finally 519 adult PLHIV on HAART were selected for the proposed study.

2.3. Data Collection Process and Tool. Weights of participants were taken by using a standard beam balance, and the scale was adjusted to zero before and after each measurement. Participant's weight was measured after removing heavy clothes and was recorded to the nearest $0.1 \mathrm{~kg}$. Height measurement of participants was taken using the standard measuring scale. Body mass index (BMI) was calculated as weight in kilograms divided by the square of height in meters $\left(\mathrm{kg} / \mathrm{m}^{2}\right)$. For the initial analysis, BMI was stratified according to the WHO criteria: $<17 \mathrm{~kg} / \mathrm{m}^{2}$ (moderate to severe malnutrition), 17 to $<18.5 \mathrm{~kg} / \mathrm{m}^{2}$ (mild malnutrition), $>18.5$ to $25 \mathrm{~kg} / \mathrm{m}^{2}$ (normal nutrition), and $>25 \mathrm{~kg} / \mathrm{m}^{2}$ (overweight and obese) [17].

Patient's medical chart was reviewed for extraction of AIDS clinical stage data and history of previous opportunistic infections (OIs) in the last 6 months. Blood samples were drawn from subjects as part of routine monthly ART followed by investigation to measure CD4 cell count. The proposed study used CD4 cell count to classify the patients into three categories according to WHO criteria: $<200$ cells $/ \mathrm{mm}^{3}$ (severe), 200-499 cells $/ \mathrm{mm}^{3}$ (moderate), and $\geq 500$ cells $/ \mathrm{mm}^{3}$ (mild).

Using the FAO Nutrition and Consumer Protection Division recommended questionnaire for data collection on individual dietary diversity score (IDDS), a record of 24hour recall of all food items eaten by the respondents was taken and classified into 12 different food groups [18]. Using FANTA (Food and Nutrition Technical Assistance), the Household Food Insecurity Access Scale (HFIAS) occurrence questions related to three different domains of food insecurity were determined.

\section{Results}

3.1. Sociodemographic Characteristics of the Respondents. More than half of the respondents (280) (53.90\%) belong to the age groups of $30-45$ years, while 83 (16\%) were between 18 and 29 years. The mean age was $41.0231 \pm$ SD 11.5055 . More than six out of ten, $333(64.20 \%)$ and $317(61.10 \%)$, of the respondents belong to Orthodox Christians and Oromo Ethnic group, respectively, while 6 (1.20\%) and 4 $(0.80 \%)$ of the participants represent Catholic and Tigre, respectively. In this study, $184(35.80 \%)$ were married. Regarding the educational status of respondents, 183 (35.30\%) were only able to attend elementary school; on the 
TABLE 1: Sociodemographic characteristics of PLHIV in Asella Town, Southeast Ethiopia.

\begin{tabular}{|c|c|c|}
\hline Variables $(n=519)$ & Frequency & Percentage (\%) \\
\hline \multicolumn{3}{|l|}{ Age } \\
\hline $18-29$ & 83 & 16 \\
\hline $30-45$ & 280 & 53.9 \\
\hline$>45$ & 156 & 30.1 \\
\hline \multicolumn{3}{|l|}{ Sex } \\
\hline Male & 209 & 40.3 \\
\hline Female & 310 & 59.7 \\
\hline \multicolumn{3}{|l|}{ Ethnicity } \\
\hline Oromo & 317 & 61.1 \\
\hline Amhara & 168 & 32.4 \\
\hline Gurage & 24 & 4.6 \\
\hline Tigray & 4 & .8 \\
\hline Others (Sidama, Hadiya, and Wolaita) & 6 & 1.2 \\
\hline \multicolumn{3}{|l|}{ Religion } \\
\hline Orthodox & 333 & 64.2 \\
\hline Muslim & 145 & 27.9 \\
\hline Protestant & 35 & 6.7 \\
\hline Catholic & 6 & 1.2 \\
\hline \multicolumn{3}{|l|}{ Educational status } \\
\hline Unable to read and write & 73 & 14.1 \\
\hline Read/write but no formal education & 68 & 13.1 \\
\hline Elementary school & 183 & 35.3 \\
\hline Secondary school & 112 & 21.6 \\
\hline Grade 12 complete & 47 & 9.1 \\
\hline College and above & 36 & 6.9 \\
\hline \multicolumn{3}{|l|}{ Occupation } \\
\hline Farmer & 164 & 31.6 \\
\hline Full-time housewife & 54 & 10.4 \\
\hline Housewife with occasional small-scale trade & 69 & 13.3 \\
\hline Merchant & 72 & 13.9 \\
\hline Governmental employee & 37 & 7.1 \\
\hline Nongovernmental employee & 19 & 3.7 \\
\hline Student & 31 & 6.0 \\
\hline Day laborer & 63 & 12.1 \\
\hline Jobless & 10 & 2 \\
\hline \multicolumn{3}{|l|}{ Marital status } \\
\hline Single & 42 & 8.1 \\
\hline Married & 184 & 35.5 \\
\hline Divorced & 144 & 27.7 \\
\hline Widowed & 111 & 21.4 \\
\hline Live-in cohabiting & 38 & 7.3 \\
\hline \multicolumn{3}{|l|}{ Monthly income (USD) } \\
\hline$<13.5$ & 131 & 25.2 \\
\hline $13.5-27$ & 167 & 32.2 \\
\hline $27-54$ & 130 & 25.1 \\
\hline $54-135$ & 91 & 17.5 \\
\hline \multicolumn{3}{|l|}{ Head of household } \\
\hline Male & 321 & 61.8 \\
\hline
\end{tabular}


TABLE 1: Continued.

\begin{tabular}{lcc}
\hline Variables $(n=519)$ & Frequency & Percentage $(\%)$ \\
\hline Female & 198 & 38.2 \\
Family size & & 52.2 \\
$<3$ & 271 & 44.1 \\
$3-6$ & 229 & 3.7 \\
$\geq 7$ & 19 & 3 \\
\hline
\end{tabular}

TABle 2: Clinical profiles and ART status of the study participants in Asella Town, Southeast Ethiopia.

\begin{tabular}{|c|c|c|}
\hline Variables $(n=519)$ & Frequency & Percentage $(\%)$ \\
\hline \multicolumn{3}{|c|}{ HIV-related symptoms 2 weeks prior to survey } \\
\hline Yes & 152 & 29.3 \\
\hline No & 367 & 70.7 \\
\hline \multicolumn{3}{|l|}{ Eating problem } \\
\hline Yes & 137 & 26.4 \\
\hline No & 382 & 73.6 \\
\hline \multicolumn{3}{|l|}{ Problems } \\
\hline Swallowing difficulty & 23 & 16.7 \\
\hline Loss of appetite & 87 & 63.5 \\
\hline Vomiting & 32 & 23.3 \\
\hline \multicolumn{3}{|c|}{ Opportunistic infections in the past 6 months } \\
\hline None & 396 & 76.3 \\
\hline 1 & 111 & 21.4 \\
\hline $2+$ & 12 & 2.3 \\
\hline \multicolumn{3}{|l|}{ Clinical stage } \\
\hline Stage I & 483 & 93.1 \\
\hline Stage II & 22 & 4.2 \\
\hline Stage III & 14 & 2.7 \\
\hline \multicolumn{3}{|l|}{ CD4 count } \\
\hline$<200$ & 40 & 7.7 \\
\hline $200-499$ & 282 & 54.3 \\
\hline$\geq 500$ & 197 & 38.0 \\
\hline \multicolumn{3}{|l|}{ Duration of HAART } \\
\hline 6 months -3 years & 184 & 35.5 \\
\hline$\geq 3$ years & 335 & 64.5 \\
\hline \multicolumn{3}{|l|}{ Side effect of HAART } \\
\hline Yes & 9 & 1.7 \\
\hline No & 510 & 98.3 \\
\hline
\end{tabular}

other hand, $36(6.90 \%)$ had studied at the college level and above. The employment status of respondents in this study was $164(31.60 \%)$ farmers and only $10(2 \%)$ of PLHIV were unemployed (Table 1).

3.2. Clinical Profiles and ART Status of Study Participants. The HIV status of patients showed that almost three out of ten, 152 (29.35\%), seen HIV-related symptom two weeks prior to the data collection period. Also, 37 (26.4\%) were not able to feed properly; majority of them, 87 (63.5\%), had loss of appetite. In this study, $483(93.10 \%)$ were at WHO clinical stage I, 123 (23.70\%) were diagnosed with opportunistic infection within the last six months, and majority, 282 (54.30\%), had moderate CD4 category with a CD4 count of 200-499 cells $/ \mathrm{mm}^{3}$. Most of the patients, 335 (64.5\%), have taken HAART for more than three years; among them, 9 (1.7\%) had ART drug side effect (Table 2).

3.3. Food- and Lifestyle-Related Characteristics. The study showed that $512(98.7 \%)$ adult patients had counseled about their feeding style after knowing their HIV status. About 461 $(88.8 \%)$ of them have received general feeding counseling. 
TABLE 3: Food- and lifestyle-related characteristics of the study participants in Asella Town, Southeast Ethiopia.

\begin{tabular}{|c|c|c|}
\hline Variables $(n=519)$ & Frequency & Percentage (\%) \\
\hline \multicolumn{3}{|c|}{ Ever had nutritional counseling } \\
\hline Yes & 512 & 98.7 \\
\hline No & 7 & 1.3 \\
\hline \multicolumn{3}{|l|}{ Type of counseling } \\
\hline Drugs & 408 & 78.6 \\
\hline Infection/illness & 31 & 6 \\
\hline General feeding & 461 & 88.8 \\
\hline \multicolumn{3}{|l|}{ Ever smoked } \\
\hline Yes & 80 & 15.4 \\
\hline No & 439 & 84.6 \\
\hline \multicolumn{3}{|l|}{ Currently smoking } \\
\hline Yes & 9 & 1.7 \\
\hline No & 510 & 98.3 \\
\hline \multicolumn{3}{|l|}{ Ever-drunk alcohol } \\
\hline Yes & 199 & 38.3 \\
\hline No & 320 & 61.7 \\
\hline \multicolumn{3}{|l|}{ Currently drinking } \\
\hline Yes & 10 & 1.9 \\
\hline No & 509 & 98.1 \\
\hline \multicolumn{3}{|l|}{ Ever-used khat/shisha } \\
\hline Yes & 131 & 25.2 \\
\hline No & 388 & 74.8 \\
\hline \multicolumn{3}{|c|}{ Currently used khat/shisha } \\
\hline Yes & 20 & 3.9 \\
\hline No & 499 & 96.1 \\
\hline \multicolumn{3}{|c|}{ Ever had hard drugs (cocaine, morphine, etc.) } \\
\hline Yes & 17 & 3.3 \\
\hline No & 502 & 96.7 \\
\hline
\end{tabular}

The most common substances ever and currently used in the study area reported by participants were khat/shisha (131 $(25.2 \%)$ and $20(3.9 \%)$, respectively). Moreover, among all patients, $17(3.3 \%)$ have taken hard drugs at least once in their lifetime (Table 3).

3.4. Dietary Diversity Scores (DDS). The most commonly eaten foods within the past 24 hours before data collection were cereals $(394 / 519,75.9 \%)$ and other foods consumed by the respondents which include condiments like coffee/tea (462/519, 89\%), legumes, nuts, and seeds (431/519, 83\%), and roots or tubers $(337 / 519,64.9 \%)$. The food groups eaten by less than $50 \%$ of the participants were fish and other seafoods, milk and milk products, fruits, vegetables, meat and meat products, eggs, and oil fat or butter (Table 4).

FAO Nutrition and Consumer Protection Division recommended questionnaire for data collection on IDDS which revealed that $61.85 \%$ of respondents had medium IDDS, $26.2 \%$ had high IDDS, and $11.95 \%$ had low IDDS (Figure 1 ).

According to the dichotomous category of the total individual food scores, 205 (39.5\%) participants had low dietary diversity ( $\leq 4$ food groups) and 314 (60.5\%) had high dietary diversity ( $\geq 5$ food groups) per 24 hours before data collection (Figure 2).

3.5. Household Food Insecurity Access Scale (HFIAS). Based on HFIAS indicator categorization, $30.2 \%$ of households had secured food, $34.8 \%$ of patients were reported to have mild Food Insecurity Access, 25.6\% of respondents have moderate Food Insecurity Access, and 9.2\% of participants were found to be severely food insecure (Table 5).

3.6. Prevalence of Undernutrition. Among 519 PLHIV participated in this study, 95 (18.3\%) respondents had $\mathrm{BMI}<$ $18.5 \mathrm{~kg} / \mathrm{m}^{2}$ with the corresponding $95 \%$ confidence interval of 14.9665-21.6423; among these, 61 (64.20\%) were females and half of $48(50.5 \%)$ were between 30 and 45 years old. From the total of 95 (18.3\%) undernourished PLHIV, 66 (12.70\%) were mildly malnourished and 29 (5.60\%) were moderately to severely malnourished. Therefore, the overall undernutrition in this study was found to be $18.3 \%$ (Figure 3).

3.7. Factors Associated with Undernutrition. The multivariable logistic regression analysis was used by taking all 
TABLE 4: Food variety consumption characteristics of the study participants in Asella Town, Southeast Ethiopia.

\begin{tabular}{|c|c|c|}
\hline Variables $(n=519)$ & Frequency & Percentage (\%) \\
\hline \multicolumn{3}{|l|}{ Whole grain feeding } \\
\hline Yes & 394 & 75.9 \\
\hline No & 125 & 24.1 \\
\hline \multicolumn{3}{|c|}{ Feeding foods made from roots or tubers } \\
\hline Yes & 337 & 64.9 \\
\hline No & 182 & 35.1 \\
\hline \multicolumn{3}{|l|}{ Vegetables } \\
\hline Yes & 177 & 34.1 \\
\hline No & 342 & 65.9 \\
\hline \multicolumn{3}{|l|}{ Fruits } \\
\hline Yes & 62 & 11.9 \\
\hline No & 457 & 88.1 \\
\hline \multicolumn{3}{|c|}{ Meat and meat products } \\
\hline Yes & 91 & 17.5 \\
\hline No & 428 & 82.5 \\
\hline \multicolumn{3}{|l|}{ Any eggs } \\
\hline Yes & 50 & 9.6 \\
\hline No & 469 & 90.4 \\
\hline \multicolumn{3}{|c|}{ Any fresh or dried fish or shellfish } \\
\hline Yes & 12 & 2.3 \\
\hline No & 507 & 97.7 \\
\hline \multicolumn{3}{|c|}{ Any foods made from beans, peas, lentil, or nuts } \\
\hline Yes & 431 & 83.0 \\
\hline No & 88 & 17.0 \\
\hline \multicolumn{3}{|c|}{ Milk or other milk products } \\
\hline Yes & 115 & 22.2 \\
\hline No & 404 & 77.8 \\
\hline \multicolumn{3}{|c|}{ Foods made with oil, fat, or butter } \\
\hline Yes & 225 & 43.4 \\
\hline No & 294 & 56.6 \\
\hline \multicolumn{3}{|l|}{ Sugar or honey } \\
\hline Yes & 143 & 27.6 \\
\hline No & 376 & 72.4 \\
\hline \multicolumn{3}{|c|}{ Other foods, such as condiments, coffee, or tea } \\
\hline Yes & 462 & 89.0 \\
\hline No & 57 & 11.0 \\
\hline
\end{tabular}

the factors into account simultaneously, and five of the most contributing factors remained to be significantly and independently associated with undernutrition which includes monthly income, whole grain feeding, insufficient quality feeding, opportunistic infection, and clinical stages. Monthly income had showed a statistically significant association with outcome variable. Those participants whose average monthly income was below 13.5 USD were 3.589 times more likely to be undernourished compared to those whose income was 54 USD and above (AOR: 3.589, 95\% CI (1.469-8.768)). It was found that daily whole grain food intake of ART patient was found to be one of the determinants of undernutrition; patients who did not feed grain and grain products in a day were almost three times more likely to be undernourished than patients who eat grain and grain products (AOR: 2.979, 95\% CI (1.2527.088)) (Table 6).

Illness of a patient within WHO clinical stage was one of the significant risk factors of undernutrition in the study area. Those patients with the illness at WHO clinical stage II were approximately three times more likely to be undernourished than WHO clinical stage I ART patients (AOR: 2.998, 95\% CI (1.269-7.083)). Patients who had a current or past six-month history of opportunistic infections were 3.683 more likely to be undernourished than those who were not infected with OIs (AOR: 3.683, 95\% CI (3.075-4.411)) (Table 6).

Yet again, insufficient quality of feeding among patents became one of the risk factors which significantly associated 


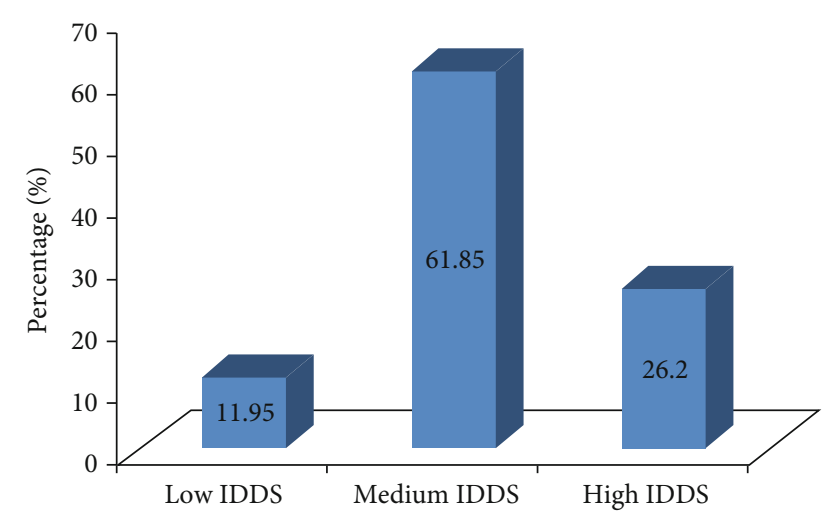

FIGURE 1: Individual dietary diversity score of the study participants in Asella Town, Southeast Ethiopia.

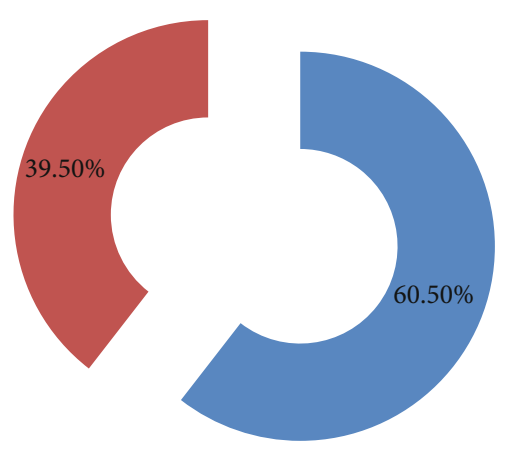

High dietary diversity score

Low dietary diversity score

Figure 2: Dichotomous category of the total individual dietary diversity scores.

with undernutrition; those patients who feed insufficient quality of food for 3-10 times per month were more than three times more likely to be undernourished than those who feed once or twice per month (AOR: 3.149, 95\% CI (1.339-7.406)) (Table 7).

\section{Discussion}

The proposed institutional-based cross-sectional study attempts to assess the prevalence of undernutrition and its associated factors among adult PLHIV and revealed that the overall prevalence of undernutrition was $18.3 \%$. Magnitude of undernutrition in PLHIV is important because it may predict disease progression and higher risk of morbidity and mortality. The presence of undernutrition is a predictor of worse outcome in HIV-infected individuals [19].

The overall prevalence of undernutrition in this study is consistent with the studies done in Nepal (19.9\%) [20] and Tanzania (18.4\%) [21]. The proportion of undernutrition of adult PLHIV in this study is higher than the studies done in Dilla, Ethiopia (12.3\%) [22] and Kenya (9.8\%) [23]. However, the prevalence of undernutrition was lowest compared to the study reports from other parts of Ethiopia, i.e., Humera (42.3\%) [24] and Dembia (23.2\%) [25], and other developing countries, such as Botswana (28.5\%) [26] and Nigeria (43.3\%) [27]. Observed discrepancy could be attributed to the clinical stage of the study participants, where majority (93.1\%) of them are found at the clinical stage I in the current study. This different result of undernutrition among different parts of the country shows that there is existence of different socioeconomic and other factors that predispose the community to the problem, probably different feeding styles of different ethnic groups in the country. As such, the difference of undernutrition may reflect due to population difference, sample, and year of study.

Undernutrition could occur in different forms and degrees. When we consider the degree of undernutrition, it varies in different circumstance. In this study, from the total undernutrition, $12.7 \%$ were mild and $5.6 \%$ were moderate to severe undernutrition. In other studies, the proportion of the degree of undernutrition was $20.3 \%$ mildly, $22 \%$ moderately to severely and $9 \%$ mildly, $3.5 \%$ moderately to severely malnourished [24-27]. From the above descriptive results, we looked at differences in the distribution of degree of undernutrition and what is clearly seen is HIV/AIDS-related undernutrition is the major problem among AIDS patients.

Descriptively, from the total participants on ART, females accounted about 310 (59.7\%), and from whom, 66 (69.4\%) were undernourished. Males accounted $40.3 \%$ of which 29 (30.6\%) were undernourished. From the total malnourished, the proportion of malnutrition was much higher in females who were on ART care (69.4\%) when compared to males (30.6\%). The proportion of women undernourished in this study is higher than the study conducted in Tigray Humera Hospital, i.e., 42.3\% [24], and Felegehiwot Referral Hospital, Bahir Dar (52\%) [28]. Probably, it might be due to different sociocultural, residence, and dietary diversity.

Results of our study showed that monthly income had showed statistically significant association with outcome variable. Participants with average monthly income below 13.5 USD were 3.589 times more likely to be undernourished when compared to those whose income was 54 USD and above (AOR: 3.589, 95\% CI (1.469-8.768)). As evidenced by other study, it revealed that there was more than $50 \%$ decrease in an average monthly household income among HIV-affected households than non-HIV-affected households because of HIV-related mortality coupled with high medical expense [29]. This might be explained as having good economic status creates better opportunity to secure food availability and to purchase varieties of nutritional foods. As a result, dietary habit or food consumption pattern of HIV-positive individuals with poor economic status may largely base on low-cost, least nutritious, and monotonous food groups.

The current study showed that WHO clinical stage is one of the significant associated factors with undernutrition; patients who were in WHO clinical stage I are less likely to develop undernutrition than a patient in stage II. Those patients with the illness at WHO clinical stage II were approximately three times more likely to be undernourished than WHO clinical stage I ART patients (AOR: 2.998, 95\% CI (1.269-7.083)) in this study. This finding is not supported by studies reported from Dilla Referral Hospital, Dilla, Ethiopia 
Table 5: Household Food Insecurity Access Scale (HFIAS) of study participants in Asella Town, Southeast Ethiopia.

\begin{tabular}{lcc}
\hline HFIAS questions $(n=519)$ & Yes $(\%)$ & No (\%) \\
\hline Worry about food & $231(44.5)$ & $288(55.5)$ \\
Unable to eat preferred foods & $295(56.8)$ & $224(43.2)$ \\
Eat a limited variety of foods & $303(58.4)$ & $216(41.6)$ \\
Eat foods that you really did not want to eat & $195(37.6)$ & $324(62.4)$ \\
Eat a smaller meal & $152(29.3)$ & $367(70.7)$ \\
Eat fewer meals in a day & $120(23.1)$ & $399(76.9)$ \\
No food to eat of any kind in the household & $28(5.4)$ & $491(94.6)$ \\
Go to sleep at night hungry & $16(3.1)$ & $503(96.9)$ \\
Go a whole day and night without eating anything & $2(0.4)$ & $517(99.6)$ \\
\hline
\end{tabular}

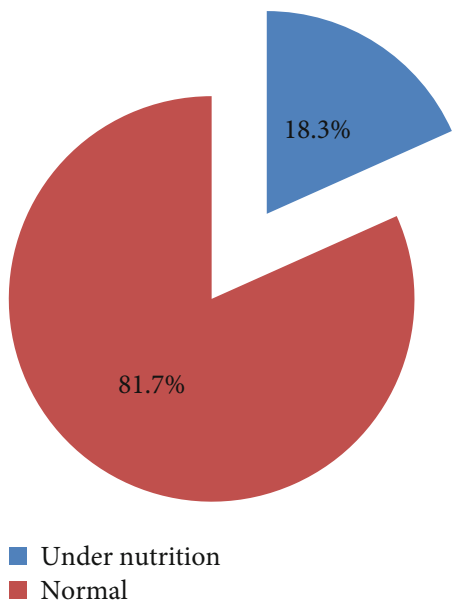

FIgURE 3: Prevalence of undernutrition among PLHIV in Asella Town, Southeast Ethiopia.

[18], where WHO clinical stages III and IV have statistically significant association with undernutrition. Other study also revealed that individuals at all stages of HIV disease are at risk of nutritional deficiency, but clinical stages show the severity of the disease from primary HIV infection to advanced stages of HIV or AIDS [30]. Undernutrition is usually encountered at the advanced phase of the HIV infection, and anthropometric measurements are lower in symptomatic HIV/AIDS patients classified by WHO stages [31]. This discrepancy might be due to the clinical stage of the study participants, where majority $(93.1 \%)$ of them are found at the clinical stage one in the current study.

Regarding OIs, individuals who were diagnosed with two or more OIs during the past six months were 3.7 times more likely to be undernourished than not diagnosed with OI (AOR: 3.683, 95\% CI (3.075-4.411)). This finding was consistent with other studies in southern Ethiopia [18] and Kenya [32]; number of previous OIs significantly associated with undernutrition. Evidences also stated that the HIV-induced immune impairment and opportunistic infections can worsen nutritional status and OIs placing PLHIV at a high risk of developing malnutrition [33].

We also assessed dietary diversity score of PLHIV which was measured by the total number of food groups that
PLHIV (any member of the household in which the PLHIV are on ART) consumed during 24 hours prior to the study. In this study, 205 (39.5\%) of the study participants had low dietary diversity, which is lower than the reports from a study in Metema Hospital (58.8\%) [34] and in Jimma University Specialized Hospital in Ethiopia (55.8\%) [35]. This shows that HIV-positive adults attending in the present study area had better dietary intake compared to what is revealed in the previous studies, with dietary diversity (the number of foods consumed across and within food groups over a reference period). This could be related to poor dietary habit of HIV-positive adults. The food types frequently consumed during 24 hours at the study period by the study participants were cereals $(75.9 \%)$, condiments/coffee/tea (89\%), legumes, nuts, and seeds (83\%), and roots or tubers (64.9\%). Fish (2.3\%) and eggs (9.6\%) were the least number of food groups consumed by PLHIV study participants. These differences could be attributed to seasonality, geographical differences, and absence of this food source in this study area.

Household access to food is a key indicator for predicting undernutrition. Majority (362) (69.8\%) of the study participants were food insecure. The result of this study is consistent with study conducted in Hossana, Ethiopia (68.5\%) [36]. However, this finding is higher than the studies conducted in Jimma Referral Hospital, Ethiopia (63.0\%) [35] and Humera, Ethiopia (40.4\%) [24] of PLHIV which were food insecure, while it is lower than the one conducted in Fitche, Ethiopia (87\%) [37] and Dembia, Ethiopia (81.6\%) [25] of the households which were food insecure. This might be due to the variation in the socioeconomic status of study areas and also could be attributed to seasonality, geographical differences, study population size, and study design. However, the crosssectional design was not able to establish temporality between the determinants and the outcome variable. Therefore, continuous nutrition therapy and early treatment of opportunistic infection at the facility level for target clients improve household income through creating employment opportunities and engaging PLHIV in different income generating activities which could possibly alleviate this predicament.

\section{Conclusion}

In this study, the prevalence of undernutrition among HIVpositive adults was $18.3 \%$. Furthermore, monthly income, 
TABLE 6: Dose response of Household Food Insecurity Access Scale (HFIAS) of study participants in Asella Town, Southeast Ethiopia.

\begin{tabular}{|c|c|c|c|c|}
\hline HFIAS questions & Frequency $(n)$ & Rarely (\%) & Sometimes (\%) & Often $(\%)$ \\
\hline Worry about food & 231 & $157(70)$ & $57(24.6)$ & $17(7.4)$ \\
\hline Unable to eat preferred foods & 295 & $181(61.4)$ & $104(35.2)$ & $10(3.4)$ \\
\hline Eat a limited variety of foods & 303 & $149(49.2)$ & $133(43.9)$ & $21(6.9)$ \\
\hline Eat foods that you really did not want to eat & 195 & $112(57.5)$ & $58(29.7)$ & $25(12.8)$ \\
\hline Eat a smaller meal & 152 & $103(67.7)$ & $44(30)$ & $5(3.3)$ \\
\hline Eat fewer meals in a day & 120 & $81(67.5)$ & $38(31.6)$ & $1(0.9)$ \\
\hline No food to eat of any kind in the household & 28 & $17(60.7)$ & $11(39.3)$ & 0 \\
\hline Go to sleep at night hungry & 16 & $14(87.5)$ & $2(12.5)$ & 0 \\
\hline Go a whole day and night without eating anything & 2 & $2(100)$ & 0 & 0 \\
\hline
\end{tabular}

TABLE 7: Bivariate and multiple logistic regression analysis of factors associated with undernutrition among people living with HIV/AIDS in Asella Town, Southeast Ethiopia.

\begin{tabular}{|c|c|c|c|c|}
\hline \multirow{2}{*}{ Variables $(n=519)$} & \multicolumn{2}{|c|}{ Undernutrition status } & \multirow{2}{*}{ COR $(95 \% \mathrm{CI})$} & \multirow{2}{*}{$\operatorname{AOR}(95 \% \mathrm{CI})$} \\
\hline & Undernourished & Normal & & \\
\hline \multicolumn{5}{|l|}{ Monthly income } \\
\hline$<500$ & 34 & 97 & $4.206(1.772-9.983)^{*}$ & $3.589(1.469-8.768)^{* *}$ \\
\hline $500-1000$ & 36 & 131 & $3.298(1.403-7.752)^{*}$ & $3.221(1.333-7.736)^{* *}$ \\
\hline $1000-2000$ & 18 & 112 & $1.929(0.770-4.828)$ & $2.201(0.856-5.663)$ \\
\hline $2000-5000$ & 7 & 84 & 1 & 1 \\
\hline \multicolumn{5}{|l|}{ Duration of HAART } \\
\hline 6 months-3years & 25 & 159 & $0.595(0.362-0.979)^{*}$ & $0.794(0.329-1.919)$ \\
\hline$\geq 3$ years & 70 & 265 & 1 & 1 \\
\hline \multicolumn{5}{|l|}{ Whole grain feeding } \\
\hline Yes & 61 & 333 & 1 & 1 \\
\hline No & 34 & 91 & $2.040(1.263-3.294)^{*}$ & $2.979(1.252-7.088)^{* *}$ \\
\hline \multicolumn{5}{|c|}{ Opportunistic infection in the last 6 months } \\
\hline None & 53 & 330 & 1 & 1 \\
\hline 1 & 33 & 85 & $2.417(1.417-3.968)^{*}$ & $2.146(0.867-5.315)$ \\
\hline $2+$ & 9 & 9 & $6.226(2.364-16.399)^{*}$ & $3.683(3.075-4.411)^{* *}$ \\
\hline \multicolumn{5}{|l|}{ Alcohol drinking } \\
\hline Yes & 38 & 161 & $1.089(0.691-1.716)$ & $1.386(0.579-3.314)$ \\
\hline No & 57 & 263 & 1 & 1 \\
\hline \multicolumn{5}{|l|}{ Clinical stage } \\
\hline Stage I & 79 & 397 & 1 & 1 \\
\hline Stage II & 12 & 17 & $3.574(1.630-7.718)^{*}$ & $2.998(1.269-7.083)^{* *}$ \\
\hline Stage III & 4 & 10 & $2.010(0.615-6.571)$ & $1.268(0.293-5.485)$ \\
\hline \multicolumn{5}{|l|}{ Insufficient quality } \\
\hline Rarely (one or twice/month) & 17 & 95 & 1 & 1 \\
\hline Sometimes (3-10 times/month) & 19 & 39 & $2.772(1.282-5.781)^{*}$ & $3.149(1.339-7.406)^{* *}$ \\
\hline Often ( $>$ ten times/month) & 1 & 24 & $0.233(0.030-1.838)$ & $0.317(0.037-2.719)$ \\
\hline
\end{tabular}

${ }^{*}$ Association on bivariate analysis. ${ }^{*}$ Statistically significant. 
whole grain feeding, OIs in the last 6 months, WHO clinical stage, and insufficient quality of food were found significantly associated with undernutrition from this study. About 39.5\% of the study participants had low dietary diversity, and majority $(69.8 \%)$ of the study participants were food insecure. Therefore, HIV treatment facility should be supported with nutritional assessment, supplementation, counseling, care, and support to patients. A comprehensive nutritional assessment and support should be provided for all patients on follow-up care. Moreover, community support to patients should be strengthened, as social determinants of health may also interact with effectiveness of treatments.

\section{Abbreviations}

$\begin{array}{ll}\text { AIDS: } & \text { Acquired immune deficiency syndrome } \\ \text { AOR: } & \text { Adjusted odds ratio } \\ \text { ART: } & \text { Antiretroviral therapy } \\ \text { BMI: } & \text { Body mass index } \\ \text { CD4: } & \text { T lymphocyte bearing CD4 receptor } \\ \text { CI: } & \text { Confidence interval } \\ \text { DHS: } & \text { Demographic and health survey } \\ \text { FAO: } & \text { Food and Agriculture Organization } \\ \text { HAART: } & \text { Highly active antiretroviral therapy } \\ \text { HFIAS: } & \text { Household Food Insecurity Access Scale } \\ \text { HIV: } & \text { Human immunodeficiency virus } \\ \text { IDDS: } & \text { Individual dietary diversity score } \\ \text { OIs: } & \text { Opportunistic infections } \\ \text { OR: } & \text { Odds ratio } \\ \text { PLHIV: } & \text { People living with HIV/AIDS } \\ \text { SSA: } & \text { Sub-Saharan Africa } \\ \text { WHO: } & \text { World Health Organization. }\end{array}$

\section{Data Availability}

The data used to support the findings of this study are available from the corresponding author upon request.

\section{Ethical Approval}

Ethical approval was obtained from ethical review committee of Department of Public Health, Arsi University (Reference Number: 120/208/10; Date: 13/07/2018). Permission was obtained from Asella Town Health Office and from each of the health facilities.

\section{Consent}

Verbal consent was taken from each participant after the purpose of the study was explained. They were told to withdraw at any time from responding to questions if they are not interested to respond. Participants were informed that all the data obtained from them will be kept confidential using codes instead of any personal identifiers. Paper-based data were kept in a locked cabinet confidentially, and computer-based data were secured with passwords. Except the research team members, no one could access patient data.

\section{Conflicts of Interest}

The authors do not have any conflict of interest.

\section{Authors' Contributions}

NMC, FL, and GT conceived and designed the study. TT conducted the study. TT, FL, and GT analyzed the data. TT, FL, and GT wrote the paper. NMC edited the manuscript.

\section{Acknowledgments}

The authors would like to thank Department of Public Health, College of Health Sciences, Arsi University, Arsi, Ethiopia, for cooperating with and supporting the research work.

\section{References}

[1] UNAIDS, Global AIDS data, 2019.

[2] WHO, Global health observatory data, HIV/AIDS, 2018.

[3] FAO, IFAD, and WFP, The State of Food Insecurity in the World 2014, Rome, 2014.

[4] UNAIDS, HIV, food security and nutrition, 2008.

[5] A. B. M. Kharsany and Q. A. Karim, "HIV infection and AIDS in Sub-Saharan Africa: current status, challenges and opportunities," The Open AIDS Journal, vol. 10, no. 1, pp. 34-48, 2016.

[6] Federal Ministry of Health, Disease Prevention and Control Department AIDS in Ethiopia, Disease Prevention and Control Department, Ministry of Health, Addis Ababa, 5th edn edition, 2005.

[7] Federal Ministry of Health, National guidelines for comprehensive HIV prevention, care and treatment in Ethiopia Addis Ababa, Ministry of Health, 2014.

[8] L. . C. Ivers, K. . A. Cullen, K. . A. Freedberg, S. Block, J. Coates, and P. Webb, "HIV/AIDS, undernutrition and food insecurity," Clinical Infectious Diseases, vol. 49, no. 7, pp. 10961102, 2009.

[9] D. Y. Gebremichael, K. T. Hadush, E. M. Kebede, and R. T. Zegeye, "Food insecurity, nutritional status, and factors associated with malnutrition among people living with HIV/AIDS attending antiretroviral therapy at public health facilities in West Shewa Zone, Central Ethiopia," BioMed Research International, vol. 2018, 9 pages, 2018.

[10] J. Jesson and V. Leroy, "Challenges of malnutrition care among HIV-infected children on antiretroviral treatment in Africa," Médecine et Maladies Infectieuses, vol. 45, no. 5, pp. 149-156, 2015.

[11] T. Hadgu, W. Worku, D. Tetemke, and H. Berhe, "Undernutrition among HIV positive women in Humera Hospital, Tigray, Ethiopia, 2013: antiretroviral therapy alone is not enough, cross sectional study," BMC Public Health, vol. 13, no. 1, p. $943,2013$.

[12] O. A. Uthman, "Prevalence and pattern of HIV-related malnutrition among women in sub-Saharan Africa: a meta-analysis of demographic health surveys," BMC Public Health, vol. 8, no. 1 , p. 226, 2008.

[13] E. A. Dodor, "Evaluation of nutritional status of new tuberculosis patients at the Effia-Nkwanta Regional Hospital," Ghana Medical Journal, vol. 42, no. 1, pp. 22-28, 2008. 
[14] B. Wasie, Y. Kebede, and A. Yibrie, "Nutritional status of adults living with HIV/AIDS at the University of Gondar Referral Hospital, Northwest Ethiopia," Ethiopian Journal of Health and Biomedical Science, vol. 3, no. 1, pp. 1-12, 2014.

[15] R. Amdemichael, M. Tafa, and H. Fekadu, "Maternal satisfaction with the delivery services in Assela Hospital, Arsi Zone, Oromia Region," Gynecol Obstet (Sunnyvale), vol. 4, no. 257, p. 2161, 2014.

[16] G. Lema, M. G. Mesfun, A. Eshete, and G. Abdeta, “Assessment of status of solid waste management in Asella Town, Ethiopia," BMC Public Health, vol. 19, no. 1, p. 1261, 2019.

[17] M. Habtamu, H. Mulu, L. Hamza, and F. Alemseged, "Prevalence of malnutrition and associated factors among hospitalized patients with acquired immunodeficiency syndrome in Jimma University Specialized Hospital, Ethiopia," Ethiopian Journal of Health Sciences, vol. 26, no. 3, p. 217, 2016.

[18] FAO, Nutrition and HIVIAIDS. A publication of the FAO food and nutrition division, 2000.

[19] S. Khatri, A. Amatya, and B. Shrestha, "Nutritional status and the associated factors among people living with HIV: an evidence from cross-sectional survey in hospital based antiretroviral therapy site in Kathmandu, Nepal," BMC Nutrition, vol. 6, no. 1, p. 22, 2020.

[20] R. Thapa, A. Amatya, D. Prasad, P. K. Bam, and M. S. Newman, "Nutritional status and its association with quality of life among people living with HIV attending public anti-retroviral therapy sites of Kathmandu Valley, Nepal," AIDS Research and Therapy, vol. 12, no. 1, p. 14, 2015.

[21] S. A. Ritte and A. T. Kessy, "Food consumption and nutritional status of people living with HIV/AIDS attending care and treatment clinics in Ilala District, Dar es Salaam," East Africa Journal of Public Health, vol. 9, pp. 33-38, 2012.

[22] S. Hailemariam, G. Tenkolu, and H. Tadesse, "Malnutrition: prevalence and its associated factors in people living with HIV/AIDS, in Dilla University Referral Hospital," Archives Public Health, vol. 71, no. 1, p. 13, 2013.

[23] Kenya National Bureau of Statistics (KNBS), Kenya Demographic and Health Survey (2008-2009), 2010.

[24] T. H. Hadgu, W. D. Worku, A. Tetemke, and H. Berhe, "Undernutrition among HIV positive women in Humera Hospital, Tigray, Ethiopia. Antiretroviral therapy alone is not enough, cross sectional study," BMC Public Health, vol. 13, no. $1,2013$.

[25] T. A. Mitiku, A. Ayele, M. Assefa, and A. Tariku, "Undernutrition and associated factors among adults living with human immune deficiency virus in Dembia District, northwest Ethiopia: an institution based cross-sectional study," Archives Public Health, vol. 74, no. 1, 2016.

[26] M. S. Nnyepi, “The risk of developing malnutrition in people living with HIV/AIDS: observations from six support groups in Botswana," South African Journal of Clinical Nutrition, vol. 22, no. 2, pp. 89-93, 2009.

[27] O. Folasire, A. Folasire, and R. Sanusi, "Measures of nutritional status and quality of life in adult people living with HIV/AIDS at a tertiary hospital in Nigeria," Food and Nutrition Sciences, vol. 6, no. 4, pp. 412-420, 2015.

[28] M. Daniel, F. Mazengia, and D. Birhanu, "Nutritional status and associated factors among adult HIV/AIDS clients in Felege Hiwot Referral Hospital, Bahir Dar, Ethiopia," Science Journal of Public Health, vol. 1, no. 1, pp. 24-31, 2013.
[29] L. Torheim, F. Ouattara, M. Diarra, F. Thiam, and I. Barikmo, "Nutrient adequacy and dietary diversity in rural Mali: association and determinants," European Journal of Clinical Nutrition, vol. 58, no. 4, pp. 594-604, 2004.

[30] C. Munthali, M. Taegtmeyer, P. G. Garner et al., "Diagnostic accuracy of the WHO clinical staging system for defining eligibility for ART in sub-Saharan Africa: a systematic review and meta-analysis," Journal of the International AIDS Society, vol. 17, no. 1, p. 18932, 2014.

[31] N. Deyessa, Y. N. Berhane, A. Alem, U. Hogberg, and G. Kullgren, "Depression among women in rural Ethiopia as related to socioeconomic factors: a community-based study on women in reproductive age groups," Scandinavian Journal of Public Health, vol. 36, no. 6, pp. 589-597, 2008.

[32] C. Agatha, K. Mary, M. Grace, and K. Rose, "Body composition and CD4 cell count of HIV sero-positive adults attending out-patient clinic in Chulaimbo Sub-District Hospital, Kenya," Pakistan Journal of Nutrition, vol. 10, pp. 582-588, 2011.

[33] S. Swaminathan, C. Padmapriyadarsini, and B. Sukumar, "Nutritional status of persons with HIV infection, persons with HIV infection and tuberculosis, and HIV-negative individuals from southern India," Clinical Infectious Diseases, vol. 46, no. 6, pp. 946-949, 2008.

[34] T. W. Amare, E. Y. Melkie, K. B. Teresa, and K. Y. Melaku, "Factors associated with dietary diversity among HIV positive adults ( $\geq 18$ years) attending ART Clinic at Mettema Hospital, Northwest Ethiopia: cross-sectional study," Journal of AIDS \& Clinical Research, vol. 6, no. 8, 2015.

[35] A. Tiyou, T. Belachew, F. Alemseged, and S. Biadgilign, "Food insecurity and associated factors among HIV-infected individuals receiving highly active antiretroviral therapy in Jimma zone Southwest Ethiopia," Nutrition Journal, vol. 11, no. 1, p. 51, 2012.

[36] A. Mekuria and J. Habtamu, "Malnutrition and associated factors among adult individuals receiving highly active antiretroviral therapy in health facilities of Hosanna Town, Southern Ethiopia," Open Access Library Journal, vol. 2, pp. 1-12, 2015.

[37] B. Tolesa, D. Demissie, T. Tesfaye, and T. Belachew, "Food insecurity and associated factors among people living with HIV attending ART Clinic in Fitche Zonal Hospital, Ethiopia," Journal of Pharmacy and Alternative Medicine, vol. 8, no. 3, pp. 8-17, 2015. 